\title{
UNDERSTANDING THE DIFFUSION OF EFFICIENT CONSUMER RESPONSE: AN AUSTRALIAN SURVEY STUDY
}

\author{
Sherah Kurnia ${ }^{7}$ \\ John M. Betts ${ }^{2}$ \\ Robert B. Johnston ${ }^{3}$ \\ 1, 3 Department of Information Systems \\ The University of Melbourne, Australia \\ ${ }^{2}$ School of Business Systems \\ Monash University, Australia
}

\begin{abstract}
Efficient Consumer Response (ECR) is designed to make the grocery industry more efficient. Although it originated in the US, the concept has been adopted in many regions. To enrich the findings of the existing studies that indicate a slow diffusion rate of ECR, this study examines ECR adoption in Australia by conducting a survey. The findings suggest that in Australia, ECR diffusion has also been slow. Differences in barriers, perceptions, and benefits experienced between manufacturers and retailers discovered in this study suggest that Australian retailers are leading manufacturers in ECR implementation and that they experience more benefits than manufacturers.
\end{abstract}

Keywords: Supply Chain Management, Exploratory Research, Survey, Innovation, Australia.

\section{INTRODUCTION}

Efficient Consumer Response (ECR) originated in the United States in late 1980's and early 1990's (Tripplet 1995) as a direct response to threats from alternative store formats which were taking market share away from the major supermarket chains. It can be defined as "a complex management theory that calls for changes in nearly all grocery work processes and practices to make the industry more efficient and responsive to consumers' needs" (Tripplet 1995, p 3). ECR has the potential to remove significant costs from the grocery supply chain through the elimination of non-value-added activities, which will in turn, result in reductions in operating costs and inventory levels, and an increase in efficiencies at all levels within the supply chain (Tripplet 1995). All this will ultimately allow the industry to offer greater value to the grocery consumers through the provision of better prices, better store assortment, better service, better convenience, and better quality products (Kurt Salmon Associates 1993; Wood 1996). The ability to provide greater value to consumer is crucial for industry survival, since competition has become more intense and consumers have gained more power. Therefore, the concept of ECR has attracted many other regions, noticeably European countries and Australia, with different motivations from the US (Leggett 1996; Wheatley 1997; Kurnia et al. 1998). However, despite the benefits and potential savings obtainable from ECR, a number of studies indicate that the diffusion rate of the concept has been slow in the US and Europe (Kurt Salmon Associates 1995; Leggett 1996; Coopers and Lybrand 1997; Greenbaum 1997; IBM 1997; Kurt Salmon Associates 1997).

Study of ECR diffusion is not well developed at present. Differences in the retail industries and the environments of different countries should be exploited to increase understanding of the relative importance of various driving forces and the above three factors to ECR diffusion and adoption. Australia has a very different market structure to other countries, in which the consumers are fewer in number and dispersed over a wide geographical area. In addition, the impetus for ECR adoption is different from that of the US and Europe. Competitive pressure from alternative store formats is not present in this country. The Australian grocery industry is dominated by very few key players which constitute the "big four" Australian retailers. The general motivation to embrace ECR, therefore, appears to be pressure from these large retailers. Other companies within the industry were forced to get involved in ECR, regardless their perceptions of the concept.

This study, therefore, aims to define the extent of ECR implementation in Australia and to identify the barriers to ECR adoption, perception of ECR and the realisation of ECR benefits in Australia. For this purpose, a survey of the Australian grocery industry was performed to explore the experience of the industry with ECR adoption. In addition to exploring the industry experience with ECR, we wanted to test the following two hypotheses:

1. In Australia, retailers are leading manufacturers in the ECR implementation.

2. Australian retailers have gained more benefits from ECR than manufacturers.

The survey findings suggest that, as in the US and Europe, the ECR diffusion rate is low in Australia. Furthermore, the results of the analysis demonstrate that both manufacturer and retailer groups differ in relation to barriers to ECR implementation, perception of ECR characteristics and the benefits gained, in such a way that they support the above two hypotheses. Because of the uniqueness of the Australian grocery industry, this study

\footnotetext{
${ }^{7}$ Address for Correspondence: Department of Information Systems, The University of Melbourne, Melbourne
} 3010, Australia. Phone: 6138344 0870, Fax: 6139349 4596, E-mail: sherahk@unimelb.edu.au 
has the potential to enrich the findings of other studies in different countries, to better understand the ECR diffusion process in general.

In the next section, we provide a brief description of ECR. We then describe the survey research method employed in this study and discuss the survey findings comprehensively. Finally, we conclude the paper by outlining the limitations to this study and suggesting some related future research.

\section{ECR AS A GROCERY SUPPLY CHAIN MANAGEMENT INITIATIVE}

ECR consists of strategic initiatives, operational programs and a number of enabling technologies, which are summarised in Figure 1.

Figure 1. ECR Components and Their Relationships (Kumia et al. 1998)

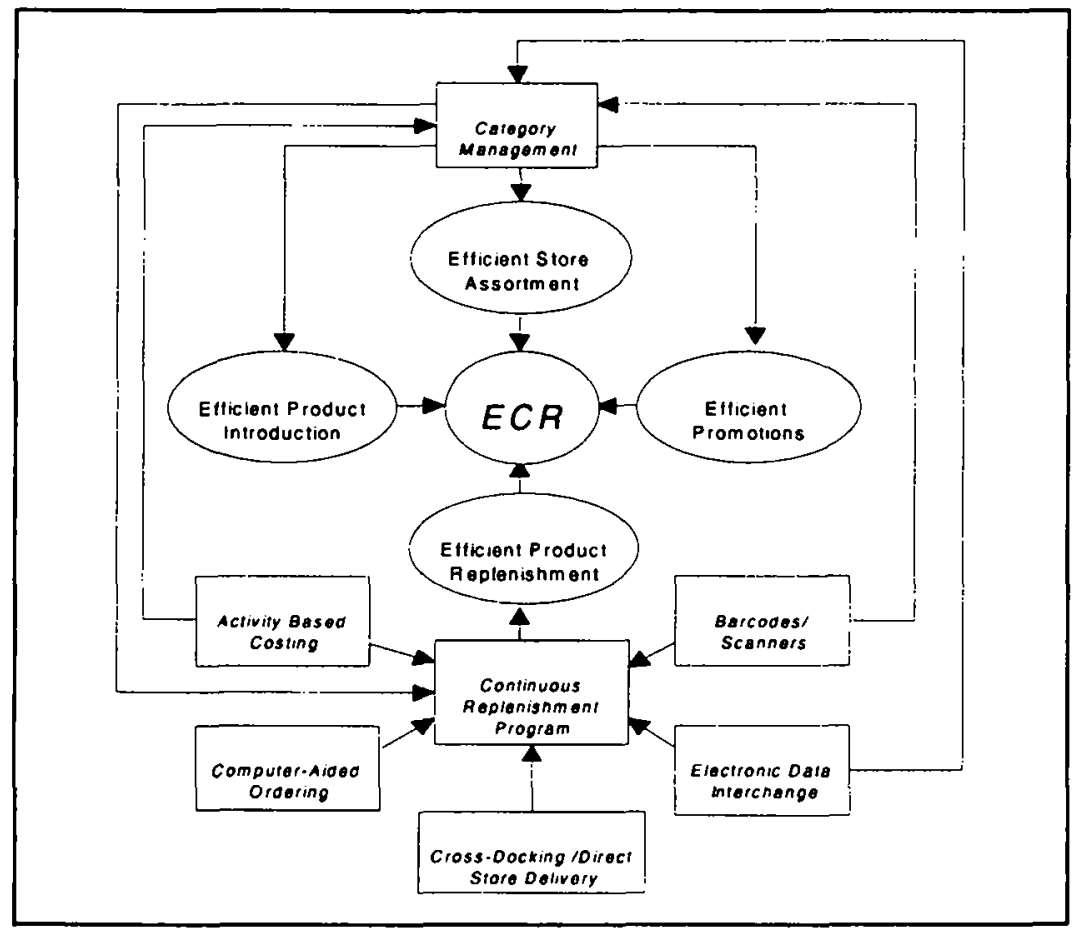

The strategic initjatives promoted by ECR are based on four areas: store assortment, promotion, product introduction, and product replenishment (Kurt Salmon Associates 1993):

- Efficient store assortment

This initiative is aimed at optimising the productivity of inventory and shelf management at the store level.

- Efficient product introduction

The objective of this initiative is to maximise the effectiveness of new product development and introduction activities, in order to reduce costs and failure rates in introducing new products.

- Efficient promotion

This initiative aims at maximising the total system efficiency of trade and consumer promotions. This can be achieved by introducing better alternative promotions, such as Pay for Performance or Every

Day Low Price program.

- Efficient product replenishment

The objective of this initiative is to optimise time and cost in the replenishment system by the provision of the right product to the right place at the right time in the right quantity and in the most efficient manner possible.

These four initiatives are supported by two operational programs, namely, Category Management (CM) and Continuous Replenishment Program (CRP). CM is an interactive business process in which retailers and manufacturers work together to manage categories as strategic business units within each store (Information Advantage 1996). It supports the first three initiatives of ECR discussed above. CRP, on the other hand, is a practice of partmering among members of a distribution channel to allow for products to flow smoothly and continuously from manufacturers to consumers (Martin 1994). It supports the efficient product replenishment initiative. 
The operational programs are, in turn, supported by a number of enabling technologies: barcode/scanner, Electronic Data Interchange (EDI), Computer Aided Ordering (CAO), cross-docking, and Activity Based Costing (ABC):

- Barcodes / Scanners

The use of barcodes and scanners is a fundamental component for ECR implementation as it enables accurate and fast information capture as well as information sharing between trading partners (EAN Australia 1997).

- Electronic Data Interchange (EDI)

Electronic Data Interchange (EDI) is defined by Emmelhainz (1990) as an inter-organisational exchange of business documents in a structured, machine-processable form.

- Computer-Aided Ordering (CAO)

Computer Aided Ordering $(\mathrm{CAO})$ is an ordering system that automatically generates orders for replenishment when the inventory level drops below a pre-determined reorder level (ECR Central 1997).

- Cross-Docking

Cross-Docking or "Flow-Through Distribution" is a direct flow of products at the distribution centre from receiving to shipping, thus eliminating additional handling and storage steps in the distribution cycle (Andel 1994).

\section{- Activity-based costing}

Activity-Based Costing is a new costing tool that works on the principle that activities (as opposed to product volumes or labour in traditional accounting) are what really affect costs. $\mathrm{ABC}$ offers a better understanding of how profits are generated, as it increases the visibility of costs in a particular environment. It can be used to gain top management commitment and leadership to support the implementation of ECR and its key components (Landry 1997).

\section{THE SURVEY RESEARCH METHOD}

We decided that a mail survey would be the most appropriate method of achieving the aims of the study, because this would allow us to reach a wide range of organisations within the Australian grocery industry. Managers, or any individual with specific knowledge on ECR-type implementations, were requested to answer the questionnaire. An initial inquiry letter describing the project and seeking participation was sent out to the senior executive of all organisations listed in the Grocery Industry Marketing Guide 1998 (Retail World 1998) to identify companies interested in ECR studies. Only those who registered some interest in ECR studies were included in the target population. Those companies that are not interested in or aware of ECR studies were expected not to be able to complete the questionnaire.

Fifty-two companies indicated their interest in participating. Two key retailers were interested in ECR studies but were not willing to participate in this study because they had just participated in another by Coopers and Lybrand (1998) which aimed to develop an ECR scorecard and the industry's level of maturity in implementing initiatives to improve supply chain performance. Thus, while the target population for this study was from fiftyfour organisations, the actual questionnaire was only sent out to fifty-two organisations. After two follow-ups were made via mail and phone, the number of returned questionnaire was 42 .

Despite the small sample size, the survey participants are representative of the population for each organisation type, due to their market share. The participants representing the 'Retailer / Wholesaler / Distributor' group, which consists of eleven organisations, control more than 30 per cent of the total market share of the Australian grocery industry. Similarly, around 40 per cent of the participants representing the 'Manufacturer / Broker' group dominate more than 50 per cent of the market share of a number of product categories within the Australian grocery industry (Food and Liquor Week 1998; Retail World 1999). In addition, the number of participants for the survey conducted by Coopers and Lybrand on behalf of the ECR Australia was only thirtysix companies, indicating the small number of the Australian companies involved in ECR at this stage (Coopers and Lybrand, 1998). Given this fact, the small sample involved in this study arguably constitutes a major part of the entire population of the Australian companies involved in ECR. Thus, the small sample of this study should by no means invalidate the findings of the survey, although it reduces the chances of obtaining results with high significance in the statistical tests of the survey responses.

The questionnaire item generation was derived from a literature review on ECR, supply chain management, and diffusion of organisational innovation. Some items were adapted from the survey questionnaire of Kurt Salmon Associates for the US and European ECR progress study, since it is desirable to replicate existing well developed questionnaires in survey research (Lucas 1991). Before sending out the questionnaire to the sample population of 52 companies, pilot tests were conducted with a logistics researcher and a practitioner who resembled the actual respondents to whom the questionnaire would be sent. 
In this study, survey responses were analysed as a function of company type. To improve the statistical significance of the results, manufacturers and brokers are classified as 'Manufacturer' while retailers, distributors and wholesalers are classified as 'Retailer'. This classification allows us to distinguish between the upstream and downstream players of supply chains. Since two key retailers were included in this study, most of the participant manufacturers are the suppliers of the retailer group. Frequency of responses for each group and rank order were used for nominal data. To find the relationships between nominal variables, the Fisher's Exact test was used because of the small sample size. For ordinal data, differences between the two groups were observed using means, which were found to be sensitive to small differences (Argyrous 1996). The Mann-Whitney test for the difference of medians, based on the rank of responses, was used for significance testing of ordinal data (Coakes and Steed 1997). In this paper, the following notations are used to indicate the level of statistical significance discovered with each test:

Difference between two groups is significant at 5 per cent level, using the Mann-Whitney test. Difference between two groups is significant at 5 per cent level, using the Fisher's Exact test.

\section{THE SURVEY FINDINGS AND DISCUSSION}

\section{Demographic Information}

Table I depicts the locations of the participants and the numbers of questionnaires sent to each location, as well as the numbers of questionnaires returned from each location. The majority of participants are located in the two most densely populated states: New South Wales (NSW) and Victoria (VIC). The 42 respondents consist of $59 \%$ manufacturers, $14 \%$ brokers, $7 \%$ retailers, $10 \%$ wholesaler and $10 \%$ retailers, as shown in Table II. Seventy percent of the respondents are SMEs, with an annual sale below $\$ 100$ million based on the 1998 financial year, and $30 \%$ of the participants are large enterprises.

\begin{tabular}{|l|l|l|l|l|}
\multicolumn{3}{c}{ Distributed } & \multicolumn{3}{c|}{ Returned } \\
\hline State & Frequency & $\%$ & Frequency & $\%$ \\
\hline NSW & 19 & 36 & 14 & 33 \\
VIC & 18 & 36 & 16 & 38 \\
QLD & 8 & 15 & 7 & 17 \\
WA & 6 & 11 & 4 & 10 \\
SA & 1 & 2 & 1 & 2 \\
\hline Total & 52 & 100 & 42 & 100 \\
\hline
\end{tabular}

Table I. Survey Distribution and Responses by State

\begin{tabular}{|l|l|l|}
\hline Company Type & Frequency & $\%$ \\
\hline Manufacturer & 25 & 59 \\
Broker & 6 & 14 \\
Retailer & 3 & 7 \\
Wholesaler & 4 & 10 \\
Distributor & 4 & 10 \\
\hline Total & 42 & 100 \\
\hline
\end{tabular}

Table II. Survey Respondents by Company Type

\section{ECR Involvement Levels}

To obtain the ECR involvement level of the participants, participants were asked to describe their level of ECR involvement from the following options: 'Fully Implemented', 'Currently Implementing', 'Considering', 'Not Sure', and 'Not Involved'. Only two respondents (5\%) have fully implemented ECR, 17 respondents $(40 \%)$ are currently implementing, four respondents $(10 \%)$ are considering, two $(5 \%)$ are not sure whether they are involved in ECR, and 17 respondents (40\%) are not involved in ECR at all. This gives us a total of 25 participants who are most likely able to provide us with useful responses for detailed ECR questions in the questionnaire.

Some reasons for non-involvement have also been identified from the responses of those 17 participants. The most frequently cited reason (cited by $65 \%$ of the respondents) is 'Do Not Understand ECR', suggesting that ECR is not widely understood in Australia. Other important reasons include 'Other priority more important', 'Lack of IT infrastructure', and 'Shortage of skilled personnel'.

\section{The Driving Forces}

From the other 25 participants, a number of driving forces to get involved in ECR bave been identified, as shown in Table III. The analysis indicates that for manufacturers, the major driving force is exogenous, whereas for the retailer it is endogenous. This finding reinforces the idea that in most supply chains, retailers are the ones who initiate the ECR program in order to improve their internal operations. Most manufacturers simply embraced the concept of ECR just to meet the requirement of their larger trading partners in order to stay in business. 


\begin{tabular}{|l|l|l|l|l|}
\cline { 2 - 6 } \multicolumn{1}{c|}{} & \multicolumn{2}{l|}{$\begin{array}{l}\text { Manufacturer } \\
(\mathrm{n}=19)\end{array}$} & \multicolumn{2}{l|}{$\begin{array}{l}\text { Retailer } \\
(\mathrm{n}=6)\end{array}$} \\
\hline Catalysts & $\%$ & Rank & $\%$ & Rank \\
\hline Pressure from Trading Partner & $74^{f}$ & 1 & $33^{f}$ & 2 \\
\hline Unpredictable Shipping Performance & 11 & & 17 & \\
\hline Under Utilization of Assets & 26 & 3 & 33 & 2 \\
\hline Declining Customer Service & 16 & & 33 & 2 \\
\hline Unpredictable Demand & 42 & 2 & 17 & \\
\hline Poor Manufacturing Efficiency & 26 & 3 & 17 & \\
\hline Inventory Unbalances & $16^{f}$ & & $68^{f}$ & 1 \\
\hline Declining Competitiveness & 26 & 3 & 17 & \\
\hline Increasing Product Costs & 16 & & 33 & 2 \\
\hline Improve Competitiveness & 21 & & 17 & \\
\hline
\end{tabular}

Table III. ECR Catalysts

\section{Implementation Level of ECR Components}

To measure the ECR implementation level, participants were requested to describe their current implementation status with the ECR components from a range of responses: 'No plan to implement', 'Keen to explore further', 'Plan to begin in 12 Months', 'In testing/pilot stage', and 'Fully operational'. For each component, they were also asked to indicate if they were pursuing the component as part of ECR. Figure 2 depicts the proportion of manufacturers and retailers who are actively pursuing the components, defined as either testing them or having fully implemented them.

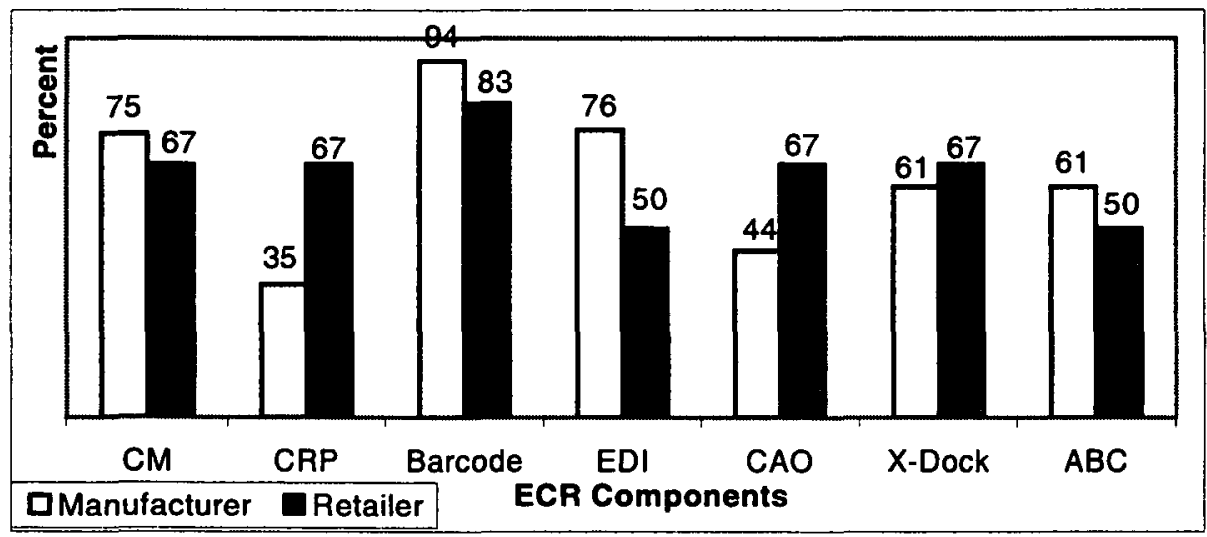

$\mathrm{n}_{\operatorname{man}}=19 ; \mathrm{n}_{\mathrm{ret}}=6$

Figure 2. Actively Pursuing the ECR Components by Company Type

The results demonstrate that a relatively large proportion of manufacturers and retailers are actively pursuing ECR components. Retailers, however, are much more enthusiastic than manufacturers about the Continuous Replenishment Program and Computer Aided Ordering implementations. This suggests that retailers are more concerned with overall supply chain management than manufacturers. Although the results suggest a high implementation level for most of the ECR components, most manufacturers indicated that they were pursuing each component not as part of the ECR program. Half of the retailers indicated that they were involved in CRP, EDI, and cross docking as part of the ECR program. This finding again supports our hypothesis that retailers are leading the ECR implementation in Australia, and manufacturers only attempt to conform to the retailers' requirement.

Further analysis indicates that there are more retailers than manufacturers who plan to begin pursuing the ECR components within 12 months. The most prominent component to be pursued is EDI, followed by CRP, CAO, and cross docking. Manufacturers, by contrast, seem to be more interested in pursuing $A B C$ than retailers. This suggests that manufacturers are more sceptical about the ECR concept than retailers, and therefore, they plan to conduct Activity Based Costing to investigate if ECR is indeed beneficial

Satisfaction Level with the ECR Initiatives

Participants were asked to describe their satisfaction level with the four ECR initiatives based on the following five scale: $-1=$ very disappointed; $-0.5=$ disappointed; $0=$ neutral; $0.5=$ satisfied; $1=$ very satisfied. The means of the responses were calculated and are presented in Table IV. 
The findings suggest that retailers are more satisfied with the ECR initiatives, particularly the Efficient Promotion and Efficient Product Introduction initiatives. Manufacturers, on the other hand, show a very low satisfaction level, suggesting that most of them were driven by retailers to get involved in ECR, without any particular interest.

\begin{tabular}{|l|l|l|l|l|}
\cline { 2 - 5 } \multicolumn{1}{c|}{} & $\begin{array}{l}\text { Efficient Store } \\
\text { Assortment } \\
\left(\mathrm{n}_{\operatorname{man}}=18 ; \mathrm{n}_{\mathrm{ret}}=5\right)\end{array}$ & $\begin{array}{l}\text { Efficient } \\
\text { Promotion } \\
\left(\mathrm{n}_{\operatorname{man}}=19 ; \mathrm{n}_{\mathrm{ret}}=5\right)\end{array}$ & $\begin{array}{l}\text { Efficient Product } \\
\text { Introduction } \\
\left(\mathrm{n}_{\operatorname{man}}=19 ; \mathrm{n}_{\mathrm{ret}}=5\right)\end{array}$ & $\begin{array}{l}\text { Efficient Product } \\
\text { Replenishment } \\
\left(\mathrm{n}_{\operatorname{man}}=17 ; \mathrm{n}_{\mathrm{ret}}=5\right)\end{array}$ \\
\hline Manufacturer & -0.11 & -0.05 & 0.13 & 0.05 \\
\hline Retailer & 0.20 & 0.40 & 0.40 & 0.10 \\
\hline
\end{tabular}

Scale:

$-1=$ very disappointed; $-0.5=$ disappointed; $0=$ neutral; $0.5=$ satisfied; $1=$ very satisfied

Table IV. Mean of the Satisfaction Level with the ECR Initiative by Company Type

\section{Implementation Problems}

A number of implementation problems have also been identified from the survey. Table $V$ depicts the top six problems encountered by manufacturers and retailers.

\begin{tabular}{|l|l|}
\hline Manufacturer ( $\mathrm{n}=19)^{*}$ & Mean \\
\hline Barriers & $3.24^{m}$ \\
\hline Conflicting priorities for resources & 3.05 \\
\hline Shortage of personnel with necessary skills & 2.94 \\
\hline Lack of clear 'roadmap' & 2.94 \\
\hline Inflexible Information Systems & 2.83 \\
\hline $\begin{array}{l}\text { Reluctance of trading partner to share } \\
\text { information }\end{array}$ & 2.67 \\
\hline 'Category managers' insufficiently trained & \\
\hline
\end{tabular}

\begin{tabular}{|l|l|}
\hline Retailer $(\mathrm{n}=6)^{*}$ & Mean \\
\hline Barriers & 3.20 \\
\hline Shortage of personnel with necessary skills & 3.00 \\
\hline Inflexible Information Systems & 3.00 \\
\hline Functional territory issues & 2.83 \\
\hline Resistance to change & 2.75 \\
\hline $\begin{array}{l}\text { Inaccurate/inappropriate performance } \\
\text { measures }\end{array}$ & $2.33^{\mathrm{m}}$ \\
\hline Conflicting priorities for resources \\
\hline
\end{tabular}

Scale:

1 = Has Not Been a Problem; 2 = Minor Problem; 3 = Moderate Problem; 4 = Major Problem

* Missing value exists

Table V. The Top Six Barriers to ECR Implementation Ranked by the Importance

The similarities in the responses indicate that both groups experience 'Conflicting priorities for resources', 'Shortage of personnel with necessary skills', and 'Inflexible Information Systems' as three of the major barriers to ECR implementation. The differences in the responses indicate that manufacturers and retailers have different implementation concerns. Other major problems indicated by manufacturers are related to the pressure enforced by retailers. They include the problem of lack of a clear roadmap in their ECR implementation and lack of training for their category managers. The problem of information sharing experienced by manufacturers indicates that retailers still have low level of trust in manufacturers. This last problem is consistent with the problems of 'Resistance to change' faced by retailers. For retailers, by contrast, the other barriers are all internal barriers, such as 'Functional territory issues' and 'Inaccurate / inappropriate performance measures'.

\section{Attitude of Management}

Participants were asked to describe the overall attitude toward ECR, of various management functions, 12 months ago and currently, based on a five-point scale: from very negative (-1) to very committed (1).

The analysis indicates that in general, over the last 12 months, there had been an improvement in the attitude of the management functions for both groups, indicating that they were becoming more convinced and enthusiastic about ECR. The results also suggest that, in general, the management functions of retailers were more committed than those of manufacturers. The difference between the two groups was significant at a $5 \%$ level for the IT management, with $\mathrm{p}$-value $=0.051$. This finding reinforced the previous findings, which indicated that retailers were leading manufacturers in ECR implementation in Australia. Interestingly, the findings demonstrated that the marketing / merchandising function of retailers had very low commitment. The difference between the two groups was significant at a $5 \%$ level, with p-value $=0.045$. The probable reason for this is that this management function is the one that interacts directly with manufacturers, who, in general, are not very enthusiastic about ECR. 


\section{The Consequences of Adoption}

Respondents were asked to indicate how ECR affected each performance measure provided in the questionnaire (see Table VI). The survey results showed some improvements in a number of performance measures. For manufacturers, the most noticeable improvement was identified in sales, customer satisfaction and marketing. The difference between manufacturers and retailers in cost reduction for marketing was significant at a $5 \%$ level $(p$-value $=0.041)$. Small reductions in the finished goods inventory and administrative costs were also experienced by the manufacturers.

\begin{tabular}{|c|c|c|}
\hline 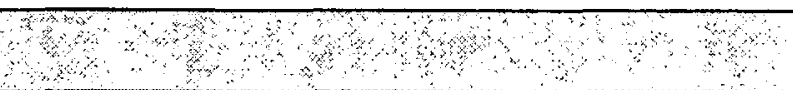 & $\begin{array}{l}\text { Manufacturer } \\
(\mathrm{n}=19) *\end{array}$ & $\begin{array}{l}\text { Retailer } \\
(n=6) *\end{array}$ \\
\hline \multicolumn{3}{|c|}{ Increase is expected } \\
\hline Sales / Turnover & 0.22 & 0.00 \\
\hline Profits & 0.27 & 0.40 \\
\hline Gross Margin Return on Inventory Investment & 0.13 & 0.40 \\
\hline Warehouse fill rate & $0.08^{m}$ & $0.60^{m}$ \\
\hline Labour productivity & 0.14 & 0.00 \\
\hline Dollar sales per square foot & 0.25 & 0.33 \\
\hline Profit margin & 0.07 & 0.40 \\
\hline Customer satisfaction & 0.43 & 0.40 \\
\hline Market share & 0.17 & 0.30 \\
\hline \multicolumn{3}{|c|}{ Decrease is expected } \\
\hline Out-of-stocks & -0.21 & -0.30 \\
\hline Finished goods inventory & -.0 .25 & -0.20 \\
\hline Invoice costs & -0.10 & -0.10 \\
\hline Raw material costs & -0.05 & -0.33 \\
\hline Packaging costs & -0.05 & -0.17 \\
\hline Manufacturing costs & -0.08 & 0.00 \\
\hline Purchasing costs & -0.05 & -0.30 \\
\hline Warehousing costs & -0.17 & -0.20 \\
\hline Transport costs & -0.21 & -0.30 \\
\hline Marketing (promotion) costs & $-0.06^{m}$ & $0.30^{m}$ \\
\hline Administrative costs & -0.03 & 0.20 \\
\hline \multicolumn{3}{|c|}{ Increase or decrease, depending on the business strategy } \\
\hline Variety of products & 0.00 & -0.10 \\
\hline Number of SKUs & 0.00 & -0.30 \\
\hline Category space allocation in store & 0.21 & 0.12 \\
\hline
\end{tabular}

Scale:

$-1=$ Reduced by over $20 \% ;-0.5=$ Reduced by up to $20 \% ; 0=$ No change; $0.5=$ Increased by up to $20 \%$; $1=$ Increased by over $20 \%$.

* Missing value exists for some performance measures.

Table VI. Changes in Performance Measures by Company Type

For retailers, the most salient improvements were identified in profit, warehouse fill rate, dollar sales per square foot, inventory level, customer satisfaction and market share. In addition, retailers experienced reductions in various costs such as for raw materials, purchasing, transport, warehouse, administrative, and marketing. Thus, consistent with the idea that the retailers were leading ECR implementation in Australia, these findings suggest that the retailers experienced more benefits than manufacturers from ECR.

Respondents were also asked if they had experienced any negative consequences of adopting ECR, as shown in Table VII. For manufacturers, 'More costs involved' was the most frequently cited consequence, followed by 'Lost of sales due to out-of-stock' and 'Employee morale problem'. For retailers, diverse responses about the consequences were given. These findings suggest that ECR implementation incurs more additional costs at the manufacturer side than at the retailer side. The most frequently cited negative consequences by retailers are 'Employee morale problem'. This is consistent with the previous finding that indicates 'Resistance to change' is one of the major implementation problems faced by retailers. This suggests that retailers are implementing ECR enthusiastically that some employees experience difficulties in coping with the changes in work practices proposed by ECR. 


\begin{tabular}{|c|c|c|c|c|}
\hline \multirow{2}{*}{ Negative Consequences } & \multicolumn{2}{|c|}{$\begin{array}{l}\text { Manufacturer } \\
(n=19)\end{array}$} & \multicolumn{2}{|l|}{$\begin{array}{l}\text { Retailer } \\
(\mathrm{n}=0)\end{array}$} \\
\hline & Percent: & Rank & Percent & Rank \\
\hline Losing Key Personnel & - & & 17 & 2 \\
\hline More Costs Involved & 53 & 1 & 17 & 2 \\
\hline Employee Morale Problem & 5 & 3 & 33 & 1 \\
\hline Diminished Customer Service Level & - & & 17 & 2 \\
\hline Losing Valuable Trading Partners & - & & - & \\
\hline Lost Sales due to Out-of-Stock & 16 & 2 & 17 & 2 \\
\hline
\end{tabular}

Table VII. Negative Consequences by Company Type

\section{The Perceived Characteristics of ECR}

Respondents were asked to describe ECR in terms of its relative advantage, compatibility with their needs, trialability of ECR components, observability of ECR benefits, complexity, switching costs, and perceived risks. Table VIII summarises the mean of the perceived characteristics of ECR by manufacturers and retailers.

\begin{tabular}{|l|l|l|}
\hline & Manufacturer $(\mathrm{n}=19)$ & Retailer $(\mathrm{n}=6)$ \\
\hline Relative Advantage & 2.53 & 3.00 \\
\hline Compatibility & 3.16 & 2.67 \\
\hline Trialability & 3.11 & 2.50 \\
\hline Observability & 2.63 & 3.33 \\
\hline Complexity & 3.39 & 3.33 \\
\hline Switching Costs & 2.95 & 3.33 \\
\hline Perceived Risks & 2.68 & 2.67 \\
\hline
\end{tabular}

Scale:

$0=$ Not Relevant; $1=$ Very Low; $2=$ Low; $3=$ Medium; $4=$ High; $5=$ Very High

Table VIII. Mean of the Perceived Characteristics of ECR

The findings demonstrate that both groups agree that ECR is a rather complex program, but the risks of getting involved in the program are low. The perceived relative advantage of ECR is higher for retailers than manufacturers. Consistently, retailers can observe the benefits of ECR more clearly than manufacturers. These results reinforce that idea that retailers are leading manufacturers. Interestingly, manufacturers' perceptions of the compatibility of ECR and the trialability of ECR components are higher than retailers and retailers perception of the switching costs for ECR is higher than manufacturers.

\section{CONCLUSIONS}

This study has provided additional insights towards understanding of the slow diffusion rate of ECR, by surveying the Australian grocery industry. While the small sample size meant that many differences observed in the data were not statistically significant, the accumulation of evidence favours the research hypotheses. As expected, the survey results demonstrate that the major driving force for manufacturers to get involved in ECR is pressure from their retailer trading partners. Retailers, on the other hand, are interested in embracing ECR in order to improve their business performance. Consequently, this affects the implementation level of ECR components among manufacturers and retailers. Most manufacturers in our study have implemented some ECR components as a stand-alone system and they show little interest in improving supply chain management following the holistic approach of ECR. Many manufacturers plan to adopt Activity Based Costing in order to gain a better understanding of what they can achieve from ECR, before embracing the whole idea. By contrast, retailers are more enthusiastic in improving the efficiency of the supply chain as a whole using the concept of ECR. A later case study provided an explanation of this observation, which revealed that manufacturers gained the least of ECR benefits and, therefore, were particularly concerned with unequal distribution of ECR costs, benefits and risks within the supply chain (Kurnia and Johnston 2001).

This study also suggests that the level of satisfaction with ECR initiatives is low among manufacturers. The later case study analysis explained that while most manufacturers do not perceive a need to embrace ECR, they must do so if they did not want to lose their major customers. By contrast, retailers have perceived real needs to change their way of business and, thus, have gained more benefits than manufacturers in implementing ECR. This, in turn, affects the satisfaction level between the two groups. In addition, the attitude of various management functions of retailers and manufacturers and their trading partners towards ECR indicated in this study reinforces the idea that retailers are driving the ECR implementation in Australia. 
In relation to the future of ECR adoption in Australia, it should be recognised that ECR is an inter-organisational innovation. In order to gain the maximum potential benefits of ECR, all participants within the supply chain need to collaborate to achieve the goals of ECR. In Australia, this kind of collaboration has not been achieved, as indicated by the survey results in general, and in particular by reluctance of retailers to share information with their trading partners, despite the fact that they are the ones who encourage the trading partners to get involved in ECR in most cases. In Australia, the major reason for not being involved in ECR is found to be lack of understanding of the concept. This suggests that the grocery industry Supply Chain Committee of Australia, which was established in 1996, needs to organise some conferences or seminars on ECR, or distribute publications on ECR to educate the industry. In addition, retailers need to educate their trading partners to ensure that the trading partners are well informed about the benefits of involvement in ECR. Without good partnership, ECR will fail to achieve its ultimate objectives, and this, will in turn, result in slow diffusion rate of ECR.

This study is part of an on-going research on diffusion of inter-organisational systems in general. Many of the findings of the survey reported in this paper have been confirmed and further elaborated through case study research (Kurnia and Johnston 2000; 2002). This project, however, will continue further by looking at supply chains as opposed to individual organisations as unit of analysis to complement the partial insights obtained from the survey into the nature of barriers to ECR diffusion, the perception of ECR and realisation of ECR benefits in Australia.

\section{REFERENCES}

Andel, T. (1994) “Define Cross-Docking Before You Do It”, Transportation and Distribution, 35(11), pp 9398.

Anonymous (1995) “Account-Specific Marketing: Working Together (Really)”, Promo/Progressive Grocer Special Report, February, p 5.

Coopers and Lybrand (1997) "Efficient Consumer Response - Europe: Value chain analysis project overview", http://www.coopers.co.uk/managementconsulting/ecr/, last access: March 1998.

Coopers and Lybrand (1998) The Grocery Industry Supply Chain Committee: 1998 Tracking Study, Grocery Manufacturer of Australia Ltd. and Australian Supermarket Institute, Sydney, Australia.

Coupe, K. (1995) “Innovation is the Key", Progressive Grocer, January, pp 29-33.

EAN Australia (1997) EAN Numbering and Barcoding of Non-Retail Items: Including an introduction to EAN application identifiers and EAN-128 barcodes, EAN Australia, Melbourne, Australia.

ECR Central (1997) "Efficient Consumer Response", http://www.ecr-cenral.com/, last access: December 1997.

Emmelhainz M A (1990) Electronic Data Interchange: A Total Management Guide. Van Nostrand Reinhold, New York.

Fowler, F. J. (1988) Survey Research Methods, Sage Publications, Inc. London.

Greenbaum, J. M. (1997) "Efficient Consumer Response: How software is remaking the consumer packaged goods industry”, Software Magazine, 17, pp 38-48.

Harris J. K., and Swatman, P. M. C. (1997) "Efficient Consumer Response (ECR): A Survey of the Australian Grocery Industry”, Proceedings of the 8th Australasian Conference on Information Systems, University of South Australia, Adelaide, pp 137-148

IBM (1997), 1997 European Retail Benchmark Report, IBM, London.

Information Advantage (1996) "What is Category Management", http://www.categorymanagement.co/whatis.html, last access: April 1997.

Jackson, W. (1988) Research Method: Rules for Survey Design and Analysis, Webcom Ltd. Canada.

Kurnia, S., Swatman, P. M. C., Schauder, D. (1998) "Efficient Consumer Response: A Preliminary Comparison of U.S. and European Experiences", Proceedings of the Eleventh International Bled Electronic Commerce Conference, Bled, Slovenia, pp 126-143.

Kurnia S and Johnston, R. B. (2000), The Need for a Processual View of Inter-Organizational Systems Adoption", Journal of Strategic Information Systems, 9(4), pp. 295-319.

Kurnia, S. and Johnston, R.B. (2001). "Adoption of Efficient Consumer Response: The Issue of Mutuality", Supply Chain Management: An International Journal, 6(5), pp 230-241.

Kurnia, S. and Johnston, R. B. (2002), "Adoption of Efficient Consumer Response in Australia: Key Issues and Challenges", Supply Chain Management: An international Journal, (In press).

Kurt Salmon Associates (1995) ECR 1995 Progress Report, Joint Industry Project on Efficient Consumer Response, Kurt Slamon Associates, New York.

Kurt Salmon Associates (1997) ECR - Europe Annual Tracking Survey, Kurt Salmon Associates, New York.

Landry, S. P., Wood, L. M. and Lindquist, T. M. (1997) “Can ABC Bring Mixed Results?” Management Accounting, 78(9), pp 28-33.

Leggett, D. (1996) "I Know What I Want....and I Want It Now", Marketing, pp 20-21. 
Lucas, H. C. (1991) “Methodological Issues in Information Systems Survey Research", In Kraemer, K. L., The Information Systems Research Challenge: Survey Research Methods. Harvard Business School, Boston, pp 273-285.

Martin, A. (1994) Infopartnering, Oliver Wight Publication, Inc. Essex Junction, VT.

Retail World (1998) Grocery Industry Marketing Guide 1998, Retail World Pty Ltd, North Paramatta, NSW. Robin, G. (1994) “Sailing into ECR's Enchanted Waters”, Stores, 76(10), pp 43-44.

Thayer, W. (1995) "How CRP Cut Inventory, Sped Turn and Grew Sales”, Frozen-Food-Age, 43, pp 1,16,17.

Tripplet, T. (1995) "More U.S. Grocers Turning to ECR to Cut Waste”, Marketing News, 3, pp 12-13.

Wheatley, M. (1997) "Efficient Consumer Response: Minding the Stores", CIO, Section 1, pp 70-78.

Wood, P. (1996) “Preparing for ECR at the Store Level”, Chain Store Age Executive, 5, May, p 230.

\section{Acknowledgements}

The authors would like to thank Professor Paula Swatman and Professor Don Schauder for their contributions in the survey administration. 